\title{
Por uma política da diferença e da identidade de gênero no esporte
}

\author{
Heroines of Sport: The Politic s of \\ Difference and Identity.
}

HARG REAVES, J ennifer.

Lond on and New York: Routledge, 2000. $284 \mathrm{p}$.

Jennifer Hargreaves é autora de Sporting Females: Critical Issues in the History and Sociology of Women's Sports e Outsiders in the Nation: Sport and Women on the Margins, dentre outras obras. Seus trabalhos estão inseridos nas análises feministas, à medida que pesquisa a participação feminina nos esportes. O livro Heroines of Sport: The Politics of Difference and Identity é dividido em sete capítulos que abordam, de forma singular, a heterogeneidade das experiências femininas nos esportes. Mulheres orig iná rias de diferentes grupos soc ia is, de distintas regiões do mundo, historic a mente ma rg ina liza das do esporte dominante, protagonizam no livro de Ha rd grea ves conquistas notáveis e intervenções heróicas. Ao longo dos seis primeiros capítulos observamos as diferentes ações, artic ulações e relações de poder que envolvem grupos de mulheres negras da África do Sul, muçulmanas dos países árabes, a borígines da Austrália e do Canadá, atletas lesbianas e atletas portadoras de deficiência física. No capítulo sete as lutas se integram em manifestações organizadas de "mulheres nos esportes", ilustradas na evolução do Movimento Desportivo Feminino Intemacional.

A autora fundamenta-se em três grandes pila res: nos estudos cultura is, direciona dos para a análise crítica das práticas, experiências e instituições cultura is e das experiências no cotidiano; nas teorias feministas, que problematiza m a desna tura liza ção dos corpos, a performatividade dosgêneros, a sexualização das identidades e a biologização das mulheres e servem como marco conceitual para discutir corpo, identidade, sexualidade, diferença e performatividade; e na sociologia do esporte, que funda a relação entre poder e cultura. Também, imana-se a os debates sobre identida de polític a e política da diferença nas sociedades capita listas, pós-colonialistase pós-modemas. $\mathrm{Na}$ área dos Esportes e da Educação Física esse movimento começa a ganhar forma, sendo possível falarde uma produção teórica sobre as questões das mulheres ou de gênero, embora nem sempre as teorias feministas sejam apontadas como fundamento epistemológico para ta is discussões, talvez pelo tom pejorativo que o termo "feminismo" a ssumiu atualmente, conforme reclama a historiadora feminista Tânia Na va rro-Swain.

O capítulo dois, "Raça, política e gênero", é sobre as lutas e as conquistas das mulheres no esporte na África do Sul, durante e após o apartheid, que deixou legado difícil de superar, no ima ginário coletivo, da superioridade branca, européia, masculina, que tinha todas as facilidades para o esporte. As mulheres negras eram e são duplamente oprimidas: pelo sistema e por seus maridos, sem nenhuma oportunidade de adesão à prática esportiva. A educação sepa rada instilava o racismo, enqua nto o esporte separado na escola instilava o sexismo. $\mathrm{Na}$ prática, o esporte era coisa para os homens, mas sobretudo para os brancos. O conselho sulafricano de esportes, de 1973, foi a primeira entidade esportiva não racista a defender que não há esporte normal numa sociedade a normal. Mas mesmo aí o esporte era coisa de homem. As mulheres era $m$ tra ta das como objetos sexua is no esporte sul-africano, o esporte feminino era trivia liza do, havia pequena parcela de mulheres em postos decisórios, a não ser em esporte exclusivamente feminino. Na luta pela sobrevivência do esporte, elas desempenhavam, a o mesmo tempo, o papel de atletas, treinadoras, árbitras, administradoras e preparadoras físicas. Como ícone da resistência e do empreendimento destaca-se a carateca Petronella Kleinsmidt, grande mãe do caratê na África, um exemplo de como negociar com idéias e estruturas dominadoras para participar no esporte. A opressão contra as mulheres negras e pobres natura lizava-se nas experiências do cotidiano, sendo raça e etnia consideradas categorias biológicas. A mulheres a fric anas somam $72 \%$ de todas as mulheres a cima dos 18 anos. 0 fim do apartheid aumentou a feminiza ção da pobreza, 
a o permitir a mobilidade das áreas rura is para as urbanas. As priorida des são tantas que o esporte fica num nível muito baixo de interesse.

0 terceiro capítulo responde à pergunta "Mulheres heróicas islâmicas, shorts ou véus?". Concentra-se sobre mulheres ícones dos países islâmicos do Oriente Médio e norte da África, desde a aplaudida marroquina Nawal El Moutawael, primeira medalha de ouro do continente a fricano, nos Jogos de Los Angeles, 1984, a té a argelina Hassiba Boulmerka, vaiada em 1992, a o retomarde Barcelona, onde brilhara nos 1.500 metros. Elas foram estrelas, mas não têm seguidoras. Para as mulheres muçulmanas as duas representam a liberdade, mas para a maioria dessa população é impróprio, para mulheres, partic iparde esportes vestidas de modo a mostrar partes do corpo. Se para o Ocidente as duas são heroínas, para os conservadores islâmicos são decadentes e pecadoras. Logo, a luta sobre seus corpos tem dimensões religiosas, políticas locais e globais, numa cultura relativamente homogênea, com 1,3 bilhão de pessoas apoiadas no isla mismo, a religião que ma is cresce no mundo depois do movimento de ressurg imento nos anos 1970 . O movimento, dirigido por teólogos, contra a ocidenta lização dos costumes regula a vida social e atinge 0 esporte, considerado produto ocidental e, sobretudo, as mulheres que o quereria $m$ praticar. Predomina a tendência fundamentalista contra a mudança, a favorda estabilidade. As crenças islâmic as se transforma ram em band eiras polític as contra o a meric a nismo, símbolo do Ocidente. As mulheres sã o consideradas as guardiã s da identidade, dos valores cultura is e religiosos, da pureza do sangue. Logo, toda a atenção se volta para mantê-las dentro de casa, na perpetuação e a perfeiç oa mento do isla mismo. A situa ção varia de país para país, desde a proibição à prática de esportes e a negação do direito de estudar, a té a obrigação de ter mulheres em todas as organizações esportivas. O corpo da mulher muçulmana deve ser modesto, estar r oberto, sem exibição. Há a vanços e recuos na liberdade de a mulher vestir-se e divertir-se; as norma variam, da a bertura à censura. A idéia de que o isla mismo é uma religião de balanço e equilíbrio ajuda as feministas a lutarem pelo direito de as mulheres pratic a rem esportes, forta lec erem o corpo, para serem melhores esposas e mães. A luta pelos direitos de eqüidade, ma is do que igualdade, soa positiva para feministas como Faezeh Hashemi. Em 1991, o Irã realizou o I Congresso de Solidariedade entre as Nações Islâmicas para Mulheres, com orientações para não misturar mulherese homens, e manter a pureza feminina. As mulheres de alguns países competiram com as roupas da cultura, incluindo véus. As competições femininas não podem ter torcida masculina. Uma das poucas saídas para as mulheres islâmicas lidarem com a pressão das ideologias políticas e religiosas é criar orga niza ções específic as, mas semp re dentro das leis do Corão, pois as pressões funda mentalistas podem voltar, em cada país, a qualquer momento, e reverter o quadro de liberdade relativa conseguido pelas mulheres. E a difícil e polêmica alternativa de Boulmerka, de conciliar as tradições ocidenta is do esporte e a doutrina religiosa, não chega a formar uma corrente ( $p$. 65). Entretanto, representa uma altemativa para as mulheres de serem sujeitos de sua própria história, e não apenas objeto das representações socia is das a utorida des polític as e religiosas de seus países. Ao final do longo capítulo, sobressa i uma questão: as mulheres esportistas islâmicas são sujeitos de suas trajetórias, ou objeto da opressão de ideologias políticas e religiosas? A resposta, prudente, da autora é que a pergunta é complexa demais, são muitos os ângulos sob os qua is pode ser respondida, e que, a o fim e ao cabo, as mulheres islâmicas avançam, criam colégios para a formação de mulheres no universo do esporte, fundam seus clubes, dirigem suas entidades, começam a participar de competições intemacionais e a ter assento no Comitê Olímpico Intemacional.

o capítulo quatro responde a outra pergunta intrigante - "mulheres indígenas esportistas: heroínas de diferença, ou objetos de a ssimilação?". Tem como foco a s mulheres nativas da Austrália e do Canadá, de várias procedências, membros do "Quarto Mundo". O processo de invasão pelos colonizadores europeus e de perda de suas terras e culturas começou, como no Brasil, por volta de 1500. Como aqui, os nativos foram considerados selvagens, inferiores. Os esportes indíg enas eram masculinos, femininos ou comuns aos dois gêneros. O capítulo é muito específico, ao detalhar as lutas e as conquistas das mulheres nativas dos dois países. O mapa rico de contrastes e de preconceitos das mulheres brancas contra as nativas, o esforço de construção política, a manifestação das lutas pela igualda de de direitos que se verifica nas associações de mulheres, as conquistascom que vêm marcando sua trajetória, tudo isso pode e deve ser transferido para a organização de movimentos de emancipação das mulheres indígenas em outros países e contextos. Compara tiva mente a o que Hargreaves 
nos apresenta na Austrália e no Canadá, cabe constatar que o Brasil está nos primórdios, pois temos os jogos indígenas, mas não vemos participação expressiva das mais de 100.000 mulheres índias na cena esportiva brasileira.

No ca pítulo cinco, "Lesbia nas nos esportes: símbolos heróic os da libertação sexual", a autora mostra como o discurso da homossexualidade, vinculada à doença e à perversão sexual, no século XIX, bem como a criação de definições essencialistas e médicas sobre gays e lesbianas nos a nos 60, refletem-se na discriminação social em face da definição sexual. Prova que o movimento de libertação gay dos anos 60 repercutiu na identidade política de gays e lesbia nas, construiu ca teg orias pa ra constituiç ão de uma identidade compartilhada e formada a partir de uma posição política, de luta em prol do segmento minoritário. Discute as bases do movimento, visita a teoria queer dos anos 90 , responsável pela crític a da noção de centro, pelo questionamento das identidades fixas e das sexualidades múltiplas. Refere Judith Butler, que rea fima o caráter disc ursivo da sexua lida de, com novas concepções de sexo, sexualidade e gênero. Ana lisa o ca ráter performativo dos corpos gays e lesbianos que, em suas a parições, exibem a encenação de si mesmos.

A autora aponta a visibilidade como a rma contra a homofobia, com o argumento de que, quanto maior for o contato entre os grupos de lesbianas, menor será o preconceito. Diz que a tletas de elite, visíveis, criam imagens positivas daslesbianas, a exemplo de Martina Navratilova, que advogou em favordaslesbianase se opôsà discriminação, tornou o pessoal político e transformou sua identidade lesbiana em identidade política. Cita também Mauresmo, tenista francesa, descrita pela imprensa como "mulher macho" por seu porte físic o musculoso, que hoje assume nova visibilida de no cenário das disc ussões queer. A visibilida de do corpo queer assume um valor político nos eventos internaciona is. As identida des lesbianas são construídas e reconstruídas, enfrentam-se nos jogos, que têm efeito de performatividade, em que o corpo é adomado e se toma espetáculo.

Jennifer apresenta o esporte gay como expressão de uma identida de compartilha da em movimentos internacionais. A criação de entidades como a Federação Européia de Esportes Gays e Lesbianos abre um novo campo de lutas pelos direitos soc ia is de lesbianas, gays, transexua is e tra vestis. As federações orga nizam campeona tos intema ciona is, como osJ ogos Gays e os Eurogames, que promovem o auto-respeito e a cultura da inclusão, como é o exemplo da partic ipação de heterossexua is e de lesbianase gays advindos de países com leis homofóbicas. Ela critica a importância dada ao sexo durante a 5a edição dos Jogos Gays, realizados em Amsterdã, em que o esporte e a performance dos/das atletas fic ou em segundo plano. A a utora conclui que cada lesbiana é um fragmento heróico de uma grande luta: como o ato de visibilidade é um desafio à heterossexualidade compulsória, as a tletas lesbia nas vivem em tensão entre sua integração social e sua lesbiandade.

O capítulo seis é sobre mulheres mutiladas ou deficientes: construind o habilidade. Enunciase o preconceito associado às portadoras de nec essida des especia is como as cegas, surdas, amputadas, portadoras de lesões de diferentes tipos. As mulheres desse segmento sã o focaliza das com atenção para seu esforço de superação, de coragem e determinação, em lutar contra o preconc eito e se a fimarnosjogos, vindo a triunfar nos esportes para-olímpicos. A autora mostra como se criaram associações, clubes, ligas e federações de portadoras de necessidades especiais. Mais uma vez, deixa claro que seu projeto é pró-ativo, pois destaca as lutas pela igualda de dos direitos. Mostra que nos países em desenvolvimento vivem $80 \%$ das mulheres mutiladas ou deficientes, que não têm oportunidades de lutar para superar a desnutrição, muito menos para ingressar no esporte. Focaliza também os projetos de construção da identidade.

No capítulo sete, intitulado "Lutando por uma nova ordem no mundo: o Movimento Desportivo Feminino Intemacional", descrevemse o surg imento e o cresc imento da orga niza ção internacional de mulheres nos esportes e na educação física, as redes de relações entre lideranças e grupos e o empoderamento das mulheres atletas no cenário intemacional. Suas luta se conquista soram a pa rec endo lenta mente. Cita a primeira organização intemacional para mulheres nos esportes e na educa ção físic a, que surgiu em 1940, com líderes em sua maioria brancas, ocidentais, da classe média, que não representam as mulheres marginalizadas e desprivilegiadas. Critica o potencial transformador do feminismo desportivo global, que tende a consolidar as relações de poder existentes, colocando em dúvida a discussão da representativida de e empoderamento de grupos minoritá rios.

A Associação Intemacional de Educação Físic a e Esportes para Mulherese J ovense Adultos, fundada em 1949, por Dorothy Ainsworth, dos 
Esta dos Unid os, to mou-se a primeira orga niza çã o internacional composta por mulheres preocupadas com os valores da educação física e esportes na vida das mulheres, sem conseguir representatividade nos países em desenvolvimento. Como reação, surge a Orga nização de Esportes Femininos Intemacional com o lema: "pense global, a ja de modo global". Em 1994 a contec eu 1a Conferência Intemacional sobre Mulherese Esportes, na Inglaterra, de onde saiu a Declaração de Brighton, cujo objetivo era promover uma cultura desportiva que possibilitasse e valorizasse o total envolvimento das mulheres em todos os a spec tos dos esportes. A 2a Conferência sobre Mulheres e Esportes realiza da em 1998 em Windhoek, Namíbia, e o surgimento do Grupo de Trabalho Internacional sobre Mulheres e Esportes (GIT) marcaram a expansão do movimento. Na 3a Conferência Mundial sobre Mulheres e Esportes, em 2002, discutiram-se dois níveis de neocolonialismo. 0 primeiro abrange as relações de poder entre dominantese subordina dos, e o segundo a grega relações de poder entre mulheres ocidentais dominantese as do mundo em desenvolvimento. A inic ia tiva desses eventos é promover o debate intemacional sobre a participação feminina nos esportes e a inclusão social, com o grande desafio de integraras nações em uma só luta: a efetiva política de desenvolvimento do esporte para as mulheres.

Hardg rea ves a ponta como desafios para a mudança: a formação de alianças com grupos representativos de minorias e grupos oprimidos em diferentes países e regiões; questões de democracia e representação, crucia is para 0 movimento se tornar global e inclusivo; a construção de pontes com o movimento polític 0 feminista e com o feminismo acadêmic o. Fruto do desenvolvimento do movimento intemacional para o esporte feminino, o discurso sobre o esporte foi substituído por um discurso da "Atividade física saudável e estilo de vida recreativo e a tivo" para mudaro foco do esporte forma lizado, elitiza do e competitivo, bem como para abranger as atividades recreativas, ma is próximas da grande maioria da população. Outra questão foi não apenas reconhecer as experiências femininas de países desenvolvidos, mas também envolver as mulheres de todo o mund o. 0 feminismo desportivo g lobal é definido pela diferença e requer linguagem estratégica que compreenda essas diferenças. Para Hardgreaves, o futuro está na união e o segredo na solidariedade feminista.

Oscapítulos da obra apresentam uma nova perspectiva do esporte feminino, como arma de construção da identidade das mulheres, como individua lida dese como membros de seus grupos de referência. A autora insiste em que na diferença reside uma força indomável, quando a proveita da e focalizada. Mostra que é complexa e difícil a ta refa de conscientizar e emancipar, e que os movimentos auto-sustentá veis a vançam, progridem, novasconquistas se verific am a cada dia, em um contexto em que homens e mulheres devem articular-se, construir a ponte para a igualda de de oportunidades. A a cessibilida de é uma utopia em várias partes do mundo e em vá rias manifestações da cultura humana. Entretanto, não encontramos, no voc abulá rio de Jennifer Hargreaves, a palavra impossível.

À semelhança de Elisabeth Badinter, ela a ponta, com lucidez, as conquistas já efetiva das, as que estão em curso e asque se podem sonhar e postular. Sua descrição é densa, sua exemplific ação é farta, com ícones da emancipação a presenta dose radiografadosem cada uma das vertentes representadas pelos diferentes capítulos. Trata-se, pois, de uma obra fundamental para os movimentos polític os e acadêmicos centrados nas injustiças e nos desa fios de gênero.

\section{Patrícia Lessa Universidade Esta dual de Maringá \\ Sebastiã o Votre Universidade Gama Filho}

